\title{
RESEARCH ON SECONDARY COLOUR OPTICAL DOT GAIN MODEL IN ELECTROSTATIC DIGITAL COLOUR PRINTINGS
}

\author{
Xiao-zhou Li, Jing-jing Liu, Xue-lin Li, Yu Liu, Ai Xu
}

Original scientific paper Screening dot is the basic printing element to reproduce continuous image and to form the printing image. Printing quality depends on the transfer quality of the screening dot. It is important to control the dot gain, sharpening, deformation, doubling and slur. In practice, some specific quality control techniques are used to monitor the screening dot variation. For dot gain control technique, multi-colour scales are often used to investigate dot gain or tone change. This article aims to investigate the secondary colour dot gain in electrostatic digital printing, by considering dot gain of the colour scales, Cyan, Magenta, Yellow, Blue, Red and Green. The relations between secondary colour dot gain and primary colour dot gain are studied. Three primary colour scales, Cyan, Magenta, Yellow, and three secondary colour scales, Blue, Red and Green, are designed from $2 \%$ to $90 \%$. The colour scales are output by electrostatic colour press and measured by spectrophotometer. The dot gain of the secondary colour scales is modelled according to the dot gain rules of the primary colour scales using multiple linear regression method. The results illustrate that the dot gain of secondary colour changes with the dot gain of primary colour scales synchronously, and that further research is needed to make for dot gain compensation and printing process control.

Keywords: dot gain; Murray-Davis formula; multiple linear regression; primary colour scale; secondary colour scale

Istraživanje modela sekundarnog kolorno optičkog rasterskog prirasta u elektrostatičkim digitalnim kolornim otiscima

Izvorni znanstveni članak

Rasterski element je osnovni tiskarski element u reprodukciji kontinuirane slike i stvaranju otisnute slike. Kvaliteta tiskanja ovisi o kvaliteti prijenosa rasterskog elementa. Važno je pratiti prirast rasterskog elementa, izoštravanje, deformaciju, udvostručenje i pojavu mrlja. U praksi se koriste neke specifične tehnike nadgledanja kvalitete u praćenju promjena rasterskih elemenata. Kao metoda praćenja prirasta rasterskih elemenata često se koriste multi kolorimetrijske skale za istraživanje prirasta rasterskih elemenata ili promjene tona. Cilj je ovoga rada ispitati prirast rasterskog elementa sekundarne boje kod elektrostatičkog digitalnog tiska, razmatrajući prirast rasterskog elementa kolorimetrijskih skala ciana, magente, žute, plave, crvene i zelene. Proučavaju se odnosi između sekundarnog kolorimetrijskog prirasta rasterskih elemenata i primarnog kolorimetrijskog prirasta rasterskih elemenata. Tri primarne kolorimetrijske skale, cian, magenta, žuta, te tri sekundarne kolorimetrijske skale, plava, crvena i zelena, dizajnirane su od $2 \%$ do $90 \%$. Kolorimetrijske su skale postavljene elektrostatičkim tiskom u boji te mjerene spektrofotometrom. Prirast rasterskog elementa sekundarnih kolorimetrijskih skala modeliran je u skladu s pravilima o prirastu rasterskih elemenata kod primarnih kolorimetrijskih skala primjenom metode višestruke linearne regresije. Rezultati pokazuju da se prirast rasterskog elementa sekundarne boje mijenja istodobno s prirastom rasterskog elementa primarnih kolorimetrijskih skala, i da je potrebno daljnje istraživanje za kompenzaciju prirasta rasterskog elementa i kontrolu postupka tiskanja.

Ključne riječi: prirast rasterskog elementa; Murray-Davis formula; višestruka linearna regresija; primarna kolorimetrijska skala; sekundarna kolorimetrijska skala

\section{Introduction}

Screening dot is the basic unit to form printing tone level and to reproduce colour in printing process $[1,2]$. And it is the basic unit of halftone image. Colour reproduction, tone level reproduction, and image texture reproduction are determined by the screening properties in colour printing $[3,4]$. Dot gain is an inherent property for printing in actual production process [5]. What we should note is that dot gain has a great effect on colour reproduction in colour printing. For example, the overall contrast of image would change because of dot gain in printing monochrome or colour halftone image $[6,7]$. Moreover, the image details and sharpness would lose too. In addition, dot gain also causes the loss of contrast, tinting of shadow tone area, and the sudden change of tone level or colour $[8,9]$. Consequently, it is important to control the dot gain and to compensate the tone change caused by the dot gain to ensure the printing quality [10, 11]. Dot gain within a control to a certain extent is good to colour reproduction.

\section{Types of dot gain}

Dot gain is a phenomenon in printing process which causes printed material to look darker than intended. Usually it is caused by halftone dots growing in area between the primary printing film and the final printed result. It is often defined as the increase in the diameter of a halftone dot during the prepress and printing processes. Dot gain is classified into two types, i.e., mechanical dot gain and optical dot gain. Mechanical dot gain is often caused by the mechanical pressure and the paper slipping caused by the distortion of the blanket in printing process $[1,9]$. The dot gain perceived is usually made up by the actions of mechanical dot gain and optical dot gain [12]. However, it is the optical dot gain that leads the key role in digital colour printing, e.g. inkjet printing and xerographic digital printing $[13,14,15]$.

\subsection{Analysis of optical dot gain}

The dot gain would not occur if the outgoing light of dot and blanket parts reflected along the incident plane respectively in digital printing $[16,17]$. However, the optical dot gain would occur when some incident light of the dot reflected from the blank part, not from the dot part or some incident light of the blank part reflected from the dot, not from the blank part. It can be shown in Fig. 1.

In Fig. 1, the light causing optical dot gain is near the injection boundary of dot area and paper surface. For incident light 1 injecting from paper surface, some, 1a, reflects from the paper surface while some, $1 \mathrm{~b}$, injects the paper inside and then goes out from the paper surface 
except the absorbed. For incident light 2 injecting from dot area, some, $2 \mathrm{~b}$, reflects from ink surface, and some, $2 \mathrm{~d}$, passes through the ink layer and goes into the paper inside and some of $2 \mathrm{~d}$ goes out of the paper through the ink layer except the absorbed. So the total amount of outgoing light or related total light reflectivity perceived can be computed as follows:

$$
R_{\mathrm{t}}=(1-A) \times R_{0}^{\prime}+A \times R_{\mathrm{s}}^{\prime},
$$

where, $R_{\mathrm{t}}$ is total light reflectivity which consists of two parts such as the reflectivity of blank paper surface, $(1-A) \times R_{0}^{\prime}$, and the reflectivity of dot area, $A \times R_{\mathrm{s}}^{\prime} . A$ is dot area. $R_{0}^{\prime}$ is the effective reflectivity of paper, and $R_{\mathrm{s}}^{\prime}$ is effective reflectivity of solid dot.

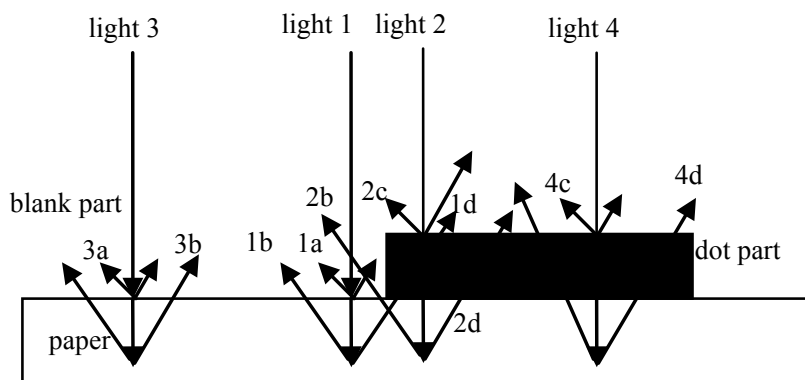

Figure 1 Optical dot gain

$1 \mathrm{a}$ - light reflected from paper surface of light $1 ; 1 \mathrm{~b}$ - light transmitted from paper inside to paper surface of light $1 ; 1 \mathrm{~d}$ - light transmitted from paper inside through ink layer to ink surface of light $1 ; 2 b-$ light transmitted from paper inside to paper surface of light $2 ; 2 \mathrm{c}-$ light refected from ink layer surface of light $2 ; 2 \mathrm{~d}-$ light transmitted from paper inside through ink layer to ink surface of light $2 ; 3 \mathrm{a}$ - light

reflected from paper surface of light $3 ; 3 b$ - light transimtted from paper inside to paper surface of light $3 ; 4 \mathrm{c}$ - ligh reflected from ink layer surface of light $4 ; 4 \mathrm{~d}$ - light transimtted from paper inside through ink layer to ink surface of light 4

\subsection{Relation between density and dot area}

The effective method to measure the cluster dot area is to measure the dot area density. And it is widely used in many colour measuring equipments. Simultaneously, a number of studies indicate that solid density has more influence on dot gain than any other factors in measuring dot gain process $[3,14,18]$. Density in printing process is usually optical density. It can be computed by logarithmic computation of the amount of incident light and outgoing light as follows:

$$
D=\lg \frac{R_{\text {in }}}{R_{\text {out }}},
$$

in which, $D$ is optical density. $R_{\text {in }}$ is the amount of incident light. And $R_{\text {out }}$ is the amount of outgoing light.

To compute the dot area of printed matter, $D_{\mathrm{s}}$ was set as the solid density and $\rho_{\mathrm{s}}$ as the corresponding reflectivity, then the relation between the density and reflectivity can be shown as follows:

$$
D_{\mathrm{s}}=\lg \frac{1}{\rho_{\mathrm{s}}}
$$

Theoretically, set the reflectance of the blank area of the substrate, e.g., paper, as 1 . Set the dot area on the paper is $a$, so the rest area of the paper is $1-a$. Then the corresponding reflectance is $a \times \rho_{\mathrm{s}}$ and $1-a$ respectively. So the total reflectance of the substrate can be computed as follows:

$\rho=a \times \rho_{\mathrm{s}}+(1-a)$.

It is shown in Fig. 2 as follows:

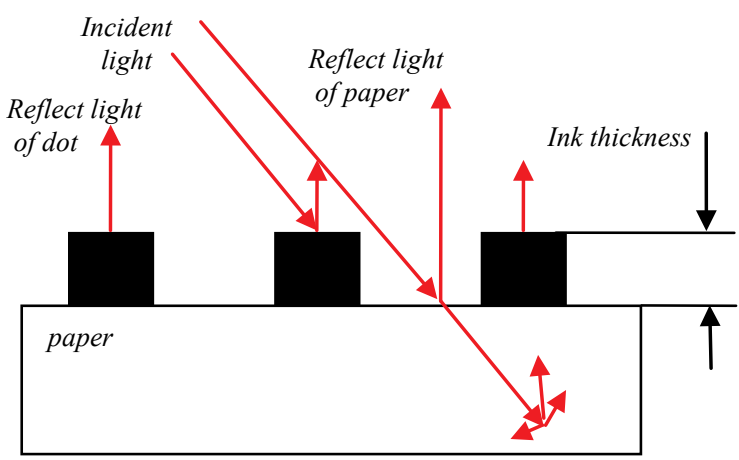

Figure 2 Computation of dot density and dot area

Thus, $D_{\mathrm{t}}$, the reflectance density of the dot area, $a$, can be computed as follows:

$D_{\mathrm{t}}=\lg \frac{1}{\rho}=\lg \frac{1}{a \times \rho_{\mathrm{s}}+(1-a)}=\lg \frac{1}{1-a\left(1-\rho_{\mathrm{s}}\right)}$.

According to Eq. (3), $\rho_{\mathrm{s}}$ can be computed as follows:

$\rho_{\mathrm{s}}=10^{-D_{\mathrm{s}}}$

Then plug Eq. (6) into the Eq. (5) and $D_{\mathrm{t}}$ can be computed as follows:

$$
D_{\mathrm{t}}=\lg \frac{1}{1-a\left(1-10^{-D_{\mathrm{s}}}\right)} \text {. }
$$

For random cluster dot area, the reflectance density $D_{\mathrm{t}}$ can be measured by densitometer or spectrophotometer. Finally, the cluster dot area can be computed according to Eq. (5), Eq. (6) and Eq. (7):

$a=\frac{1-10^{D_{\mathrm{t}}}}{1-10^{D_{\mathrm{s}}}}$

in which, $a$ is the cluster dot area of printing sample to be measured. $D_{\mathrm{t}}$ is reflectance density, and $D_{\mathrm{s}}$ is solid density. Eq. (8) is the famous formula to compute the relation between dot area and dot density, i.e., MurrayDavis formula [5, 19, 20,21]. Although some corrections have been done to the formula by the researchers in this area, e.g., Yule-Nielson formula [21, 22], Murray-Davis formula remains to be the most popular model in measuring dot area and dot density. In this paper, MurrayDavis formula was used to compute the relation between dot area and dot density. 


\section{Modelling and experiment part}

3.1 Development, analysis and hypothesis of secondary colour scale dot gain model

Given the primary dot area of primary dot area is $S_{0}$ and the measured dot areas of primary are $S_{\mathrm{C}}, S_{\mathrm{Y}}$, and $S_{\mathrm{M}}$ respectively. So the corresponding secondary colour scale dot areas are $S_{\mathrm{B}}, S_{\mathrm{R}}$, and $S_{\mathrm{G}}$. Theoretically, the final perception of dot paralleling is the same as that of dot overprinting according to halftone image reproduction law [23]. For secondary colour scale, Blue is made up by primary colour Cyan and Magenta scale. There would be several cases as follows:

Case 1: Cyan and Magenta colour scale do not overlap at all (Fig. 3). So the total dot gain of this scale can be shown as follows:

$\Delta S_{\mathrm{B}}=\Delta S_{\mathrm{C}}+\Delta S_{\mathrm{M}}$

in which, $\Delta S_{\mathrm{C}}$ is dot gain of Cyan colour scale. $\Delta S_{\mathrm{M}}$ is dot gain of Magenta colour scale. $\Delta S_{\mathrm{B}}$ is dot gain of secondary colour, Blue colour scale.

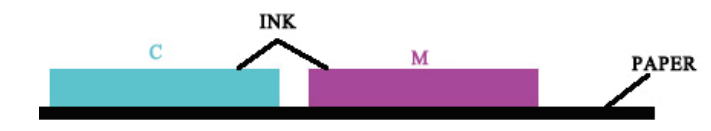

Figure 3 Case 1: Cyan dot does not overlap with Magenta dot at all

Case 2: Cyan and Magenta colour scale overlap completely (Fig. 4). So the total dot gain of blue scale can be shown as follows:

$\Delta S_{\mathrm{B}}=\max \left(\Delta S_{\mathrm{C}}, \Delta S_{\mathrm{M}}\right)$,

where, $\Delta S_{\mathrm{B}}, \Delta S_{\mathrm{C}}$ and $\Delta S_{\mathrm{M}}$ have the same meaning in Eq. (9). Max is to find the maximum dot gain from Cyan dot gain and Magenta dot gain.

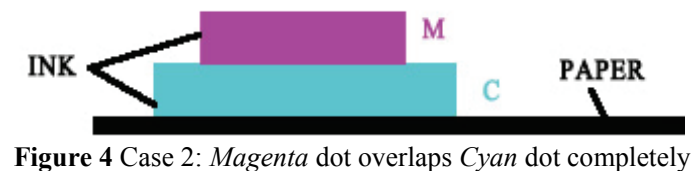

Case 3: Cyan dot area partly overlaps Magenta dot area (Fig. 5). For this case, secondary colour, Blue, consists of both overlapping and paralleling case. So the total dot gain can be shown as follows:

$\Delta S_{\mathrm{B}}=S_{\mathrm{C}}+S_{\mathrm{M}}-\Delta S-2 S_{0}$,

in which, $\Delta S$ is the overlapped dot area. $S_{0}$ is the primary dot area.

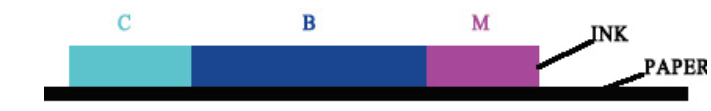

Figure 5 Case 3: Cyan dot area partly overlaps Magenta dot area

Therefore, dot gain of secondary colour scale, $\Delta S_{\mathrm{B}}$, can be illustrated as the function of dot gain of the primary colour scale, $\Delta S_{\mathrm{C}}$ and $\Delta S_{\mathrm{B}}$. And it can be expressed as follows:
$\Delta S_{\mathrm{B}}=f\left(\Delta S_{\mathrm{C}}, \Delta S_{\mathrm{M}}\right)$

Further it can be shown as:

$\Delta S_{\mathrm{B}}=a \times \Delta S_{\mathrm{C}}+b \times \Delta S_{\mathrm{M}}+c$,

in which, $c$ is adjustment coefficient. And this prototype model of dot gain of secondary colour scale is developed. Similarly, the prototype of dot gain of secondary colour scale, Red and Green, can be formed using the same method above. In this paper the prototype model is simulated using Multiple Linear Regression method as follows.

\subsection{Multiple Linear Regression}

Secondary colours, Red, Blue and Green, are obtained by overlapping or paralleling the primary colour, Cyan, Magenta and Yellow in this paper. So the dot change of Red, Green and Bluecolour scale is determined by the dot change of Cyan, Magenta, and Yellow colour scale. In particular, the dot change of Blue colour scale is determined by Cyan colour scale and Magenta colour scale. The dot change of Red colour scale is determined by Yellow colour scale and Magenta colour scale. And the dot change of Green colour scale is determined by Yellow colour scale and Cyan colour Scale. According to the above analysis, multiple linear regression method is used to analyze the dot gain of secondary colour scale in this paper.

The common form of multiple linear regression model can be shown as follows:

$Y_{i}=\beta_{0}+\beta_{1} X_{1 i}+\beta_{2} X_{2 i}+\ldots+\beta_{k} X_{k i}+\varepsilon_{i}, i=1,2, \ldots, n$

In which, $k$ is the number of variables. $\beta_{j}(j=1,2, \ldots$, $k$ ) is regression coefficient.

For the parameter estimation of Eq. (14), it can be done by least square method or maximum likelihood estimation method under the condition of satisfying the minimum of error sum of squares. Given $\left(x_{11}, x_{12}, \ldots, x_{1 p}\right.$, $\left.y_{1}\right), \ldots,\left(x_{n 1}, x_{n 2}, \ldots, x_{n p}, y_{n}\right)$ to be a group samples, and maximum likelihood estimation method is used.

Set $\hat{b}_{0}, \hat{b}_{1}, \ldots, \hat{b}_{p}$. When $b_{0}=\hat{b}_{0}, b_{1}=\hat{b}_{1}, \ldots, b_{p}=\hat{b}_{p}$, $Q=\sum_{i=1}^{n}\left(y_{i}-b_{0}-b_{1} x_{i 1}-\ldots-b_{p} x_{i p}\right)^{2}$ has the minimum value. Take partial derivative to each component of $Q$ and make them equal to zero, i.e.,

$$
\begin{aligned}
& \left\{\begin{array}{l}
\frac{\partial Q}{\partial b_{0}}=-2 \sum_{i=1}^{n}\left(y_{i}-b_{0}-b_{1} x_{i 1}-\ldots-b_{p} x_{i p}\right)=0 \\
\cdots \\
\frac{\partial Q}{\partial b_{j}}=-2 \sum_{i=1}^{n}\left(y_{i}-b_{0}-b_{1} x_{i 1}-\ldots-b_{p} x_{i p}\right) x_{i j}=0
\end{array}\right. \\
& j=1,2, \ldots, p .
\end{aligned}
$$

And Eq. (15) is simplified to Eq. (16) as follows: 


$$
\left\{\begin{array}{l}
\sum_{i=1}^{n} y_{i}=b_{0} n+b_{1} \sum_{i=1}^{n} x_{i 1}+b_{2} \sum_{i=1}^{n} x_{i 2}+\cdots+b_{p} \sum_{i=1}^{n} x_{i p} \\
\sum_{i=1}^{n} x_{i 1} y_{i}=b_{0} \sum_{i=1}^{n} x_{i 1}+b_{1} \sum_{i=1}^{n} x_{i 1}^{2}+b_{2} \sum_{i=1}^{n} x_{i 1} x_{i 2}+\cdots+b_{p} \sum_{i=1}^{n} x_{i 1} x_{i p} \\
\cdots \\
\sum_{i=1}^{n} x_{i p} y_{i}=b_{0} \sum_{i=1}^{n} x_{i p}+b_{1} \sum_{i=1}^{n} x_{i p} x_{i 1}+b_{2} \sum_{i=1}^{n} x_{i p} x_{i 2}+\cdots+b_{p} \sum_{i=1}^{n} x_{i p}^{2}
\end{array}\right.
$$

Then set

$$
Y=\left(\begin{array}{l}
y_{1} \\
y_{2} \\
\vdots \\
y_{n}
\end{array}\right), X=\left(\begin{array}{ccccc}
1 & x_{11} & x_{12} & \cdots & x_{1 p} \\
1 & x_{21} & x_{21} & \cdots & x_{2 p} \\
\vdots & \vdots & \vdots & \cdots & \vdots \\
1 & x_{n 1} & x_{n 2} & \cdots & x_{n p}
\end{array}\right), B=\left(\begin{array}{l}
b_{0} \\
b_{1} \\
\vdots \\
b_{p}
\end{array}\right)
$$

respectively, Eq. (17) can be set as follows:

$$
X^{\prime} Y=X^{\prime} X B \text {. }
$$

Therefore, maximum likelihood estimator is obtained:

$$
\hat{B}=\left(\begin{array}{c}
\hat{b}_{0} \\
\hat{b}_{1} \\
\vdots \\
\hat{b}_{n}
\end{array}\right)=\left(X^{\prime} X\right)^{-1} X^{\prime} Y
$$

So the estimator of $u\left(x_{1}, x_{2}, \cdots, x_{p}\right)=b_{0}+b_{1} x_{1}+\cdots+b_{p} x_{p}$ is:

$$
\hat{y}=\hat{b}_{0}+\hat{b}_{1} x_{1}+\cdots+\hat{b}_{p} x_{p}
$$

And Eq. (19) is the $p$ variables experience linear regression equation. In this paper, secondary colour scale consists of two primary colour scales, so set $p=2$. And such process is to solve the two variables linear regression equation.

\subsection{Experiment}

Dot gain is inevitable in printing process. Even in non-impact printing, optical gain is still in dot area [14]. Six colour scales were designed and output in this paper (Fig. 6). From the top to the bottom the colour scales are Cyan, Magenta, Yellow, Blue, Green and Red respectively. And static digital printing was chosen as the output mode and the dot area of primary colour scale, Cyan, Magenta and Yellow, were measured. The dot areas of second colour scale, Blue, Red and Green were also measured. 500 samples were output using Konica Minolta bizhub Press C6000 and about 50 samples were extracted randomly and measured by spectrophotometer. The average values are shown in Tab. 1 and Tab. 2. And coated color laser printing paper was used as printing substrate. The weight is $120 \mathrm{~g} / \mathrm{m}^{2}$. X-Rite SpectroEye LT was used to measure the color patch with the viewing condtion of D $65,2^{\circ}$ standard viewing angle and $45^{\circ} / 0^{\circ}$ of

\begin{tabular}{|c|c|c|c|c|c|c|c|c|c|c|c|c|c|c|c|c|}
\hline \multicolumn{17}{|c|}{ Dot area of primary colour scale } \\
\hline \multicolumn{2}{|c|}{ Primary dot area } & 0 & 2 & 4 & 6 & 8 & 10 & 20 & 30 & 40 & 50 & 60 & 70 & 80 & 90 & 100 \\
\hline \multirow{3}{*}{$\begin{array}{l}\text { Output } \\
\text { dot Area }\end{array}$} & $C$ & 0 & 6 & 9 & 14 & 18 & 19 & 34 & 46 & 57 & 64 & 77 & 86 & 93 & 98 & 100 \\
\hline & $M$ & 0 & 4 & 10 & 14 & 17 & 19 & 30 & 42 & 54 & 63 & 76 & 84 & 92 & 98 & 100 \\
\hline & $Y$ & 0 & 4 & 10 & 15 & 18 & 21 & 35 & 50 & 63 & 71 & 82 & 88 & 94 & 99 & 100 \\
\hline
\end{tabular}
geometry. CIE1931 standard observers was used in this paper.

\begin{tabular}{|c|c|c|c|c|c|c|c|c|c|c|c|c|c|c|c|c|}
\hline \multicolumn{17}{|c|}{ Dot area of secondary colour scale } \\
\hline \multicolumn{2}{|c|}{ Primary dot area } & 0 & 2 & 4 & 6 & 8 & 10 & 20 & 30 & 40 & 50 & 60 & 70 & 80 & 90 & 100 \\
\hline \multirow{3}{*}{$\begin{array}{l}\text { Measured dot } \\
\text { area }\end{array}$} & $B$ & 0 & 6 & 13 & 19 & 21 & 24 & 41 & 54 & 64 & 75 & 84 & 91 & 94 & 98 & 100 \\
\hline & $G$ & 0 & 4 & 9 & 16 & 20 & 23 & 35 & 52 & 64 & 72 & 82 & 89 & 94 & 99 & 100 \\
\hline & $R$ & 0 & 6 & 13 & 21 & 24 & 28 & 42 & 59 & 73 & 80 & 89 & 93 & 96 & 99 & 100 \\
\hline
\end{tabular}

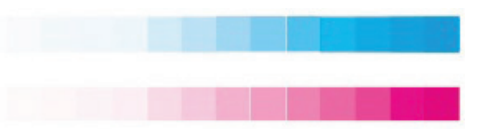

Figure 6 Colour scales of Cyan, Magenta, Yellow, Blue, Green and Red

Table 1 Primary colour dot area

Dot area of primary colour scale

Table 2 Secondary colour dot area

\section{Results and discussion}

The research in this paper comprised the research of dot gain of primary colour Cyan, Yellow and Magenta, dot gain of secondary colour Blue, Red and Green, and the relation model between secondary colour and primary colour. The results of the research were put into correlation in order to get the objective recommendations of the relation between secondary colour dot gain and primary colour dot gain for the xerographic digital printing.

\subsection{Primary dot gain curves}

The research of dot gain was performed on fields of the colour scales in the range from 2 to $90 \%$ screen value. By calculation of dot gain for the designed colour scales the curves for the primary colour were constructed 
as the average value of all Cyan, Magenta and Yellow samples. The obtained results are shown in Fig. 7.

In Fig. 7, dot gain of Cyan, Magenta and Yellow is basically the same in the high-light area. Dot gain of Yellow is the most obvious or serious in light area $(20 \div$ $40 \%$ ) and mid-tone area $(40 \div 60 \%)$, while dot gain of Magenta is less serious in the same area. However, dot gain of the three primary colour scales tends to be basically the same in the shadow area $(70 \div 100 \%)$. The point is that dot gain is most serious in $40 \%$ tone area, not in $50 \%$ tone area because it is dependent on dot shape.

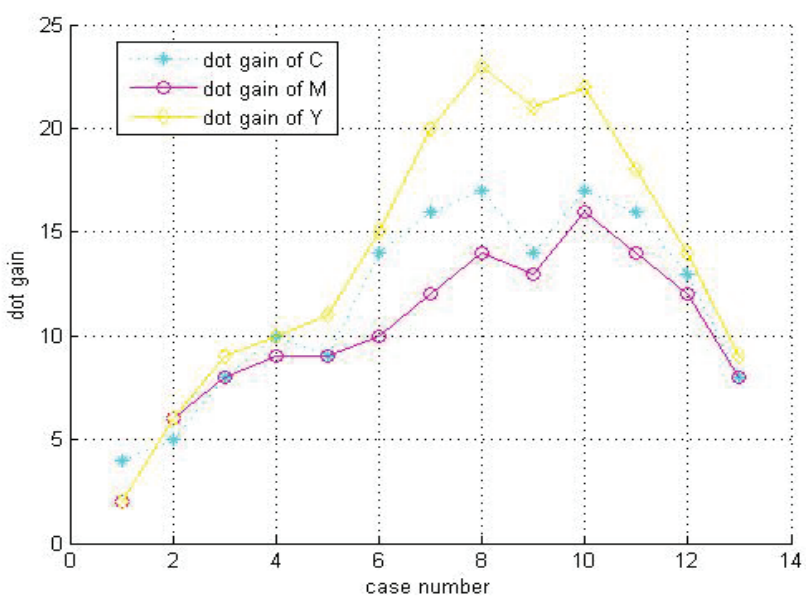

Figure 7 Dot gain of primary colour scales, Cyan, Magenta and Yellow

\subsection{Modelling for secondary colour dot gain}

According to the above analysis, assume that secondary colour dot gain depends on the primary colour dot gain. For secondary colour Blue, its dot gain is based on dot gain of primary colour, Cyan and Magenta according to the multiple linear regression method. Dot gain of Blue is given to have the follow relations with Cyan and Magenta according to Eq. (19):

$$
\Delta B=b_{0}+b_{1} \Delta C+b_{2} \Delta M
$$

Similarly, secondary colours Green and Red have similar relations with primary colour Cyan, Magenta and Yellow.

$$
\left\{\begin{array}{l}
\Delta B=b_{0}+b_{1} \Delta C+b_{2} \Delta M \\
\Delta G=g_{0}+g_{1} \Delta C+g_{2} \Delta Y . \\
\Delta R=r_{0}+r_{1} \Delta M+r_{2} \Delta Y
\end{array} .\right.
$$

Eq. (21) also can be expressed as:

$$
\Delta S(B, G, R)=A \cdot \Delta P(C, M, Y)
$$

where, $\Delta S$ is dot gain of secondary colour, $\Delta P$ is dot gain of primary colour and $A$ is conversion matrix.

50 samples were extracted from the output samples randomly and were measured by spectrophotometer to get the dot gain data. The average data is shown in Tab. 2 . Multiple linear regression method was used to compute the related coefficient for Eq. (21) and Eq. (22). And the result is shown as follows:

$$
A=\left(\begin{array}{lll}
b_{0} & b_{1} & b_{2} \\
g_{0} & g_{1} & g_{2} \\
r_{0} & r_{1} & r_{2}
\end{array}\right)=\left(\begin{array}{ccc}
-0.6203 & 1.3865 & 0.0955 \\
0.0033 & 0.0418 & 1.0147 \\
3.4423 & -0.9240 & 1.8397
\end{array}\right)
$$

Then the prototype of relation between secondary colour scale dot gain and primary colour scale dot gain is developed as follows.

$$
\left\{\begin{array}{l}
\Delta B=-0.6203+1.3865 \Delta C+0.0955 \Delta M \\
\Delta G=0.0033+0.0418 \Delta C+1.0147 \Delta Y \\
\Delta R=3.4423-0.9240 \Delta M+1.8397 \Delta Y
\end{array}\right.
$$

So the dot gain of secondary colour scale can be calculated based on the dot area of primary colour scale. Then the measured dot gain (Tab. 2) and calculated dot gain can be compared and some effective analysis can be done. Finally, the effective prototype system for secondary colour scale dot gain compensation and prediction system based on the primary colour scale dot gain can be developed.

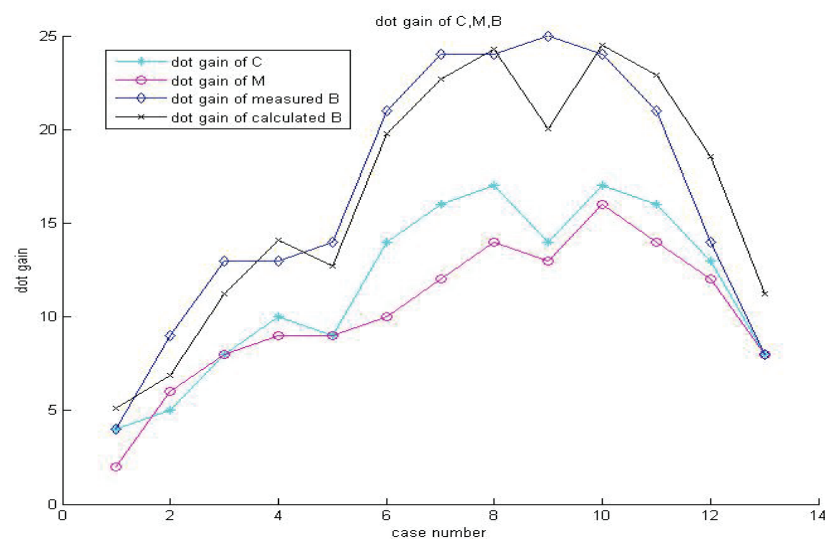

Figure 8 Dot gain of Cyan, Magenta, measured Blue and Calculated Blue

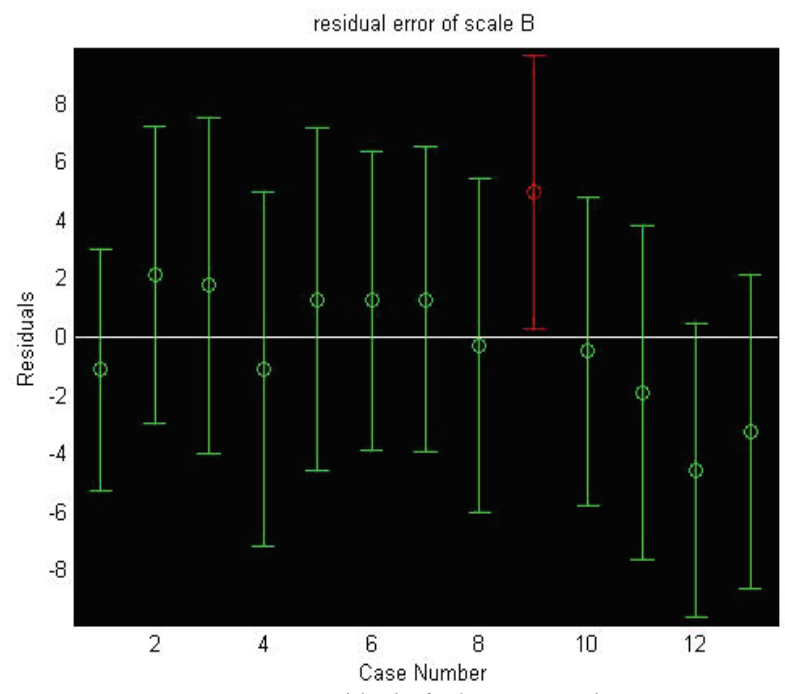

Figure 9 Residual of Blue regressed

\subsection{Evaluation and discussion}

According to the result, Tab. 1 and Tab. 2, the relation between measured dot gain and calculated dot gain of Blue based on primary Cyan and Magenta is shown in Fig. 8. And the residual plot of calculated 
secondary dot gain is shown in Fig. 9. In a similar way, the relation between measured dot gain and calculated dot gain of Red based on primary Magenta and Yellow is shown in Fig. 10. And the residual plot of calculated secondary dot gain is shown in Fig. 11. For secondary Green, the comparison was shown in Fig. 12 and Fig. 13.

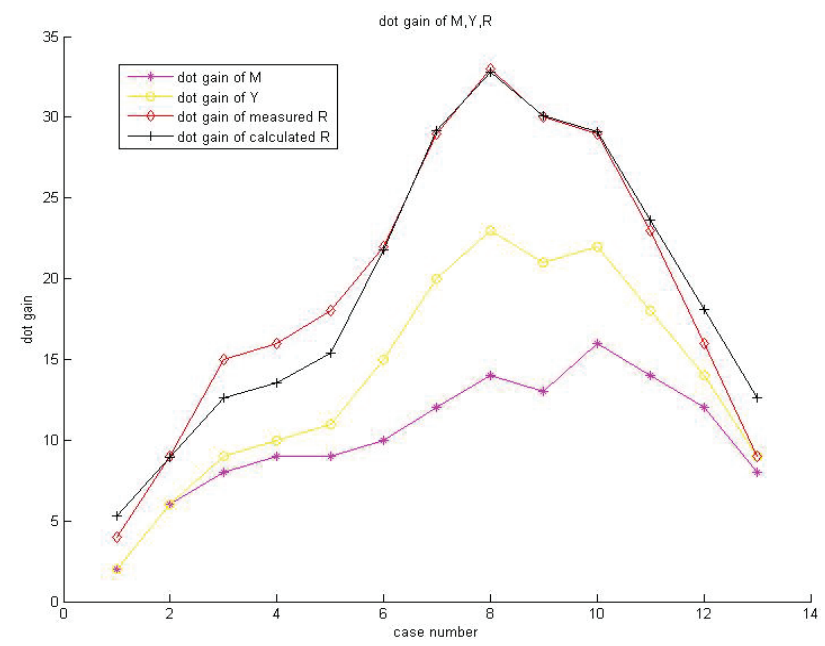

Figure 10 Dot gain of Yellow, Magenta, measured Red and Calculated Red

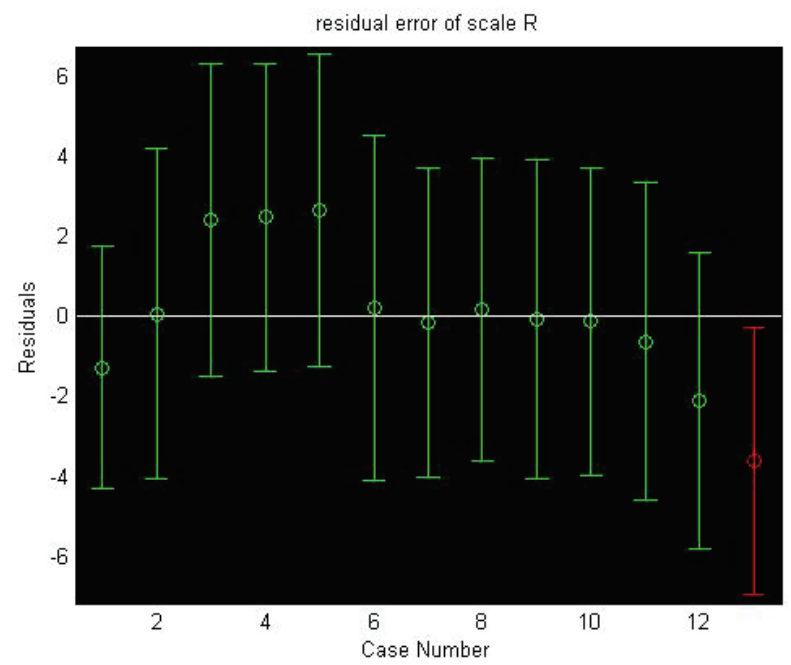

Figure 11 Residual of Red regressed

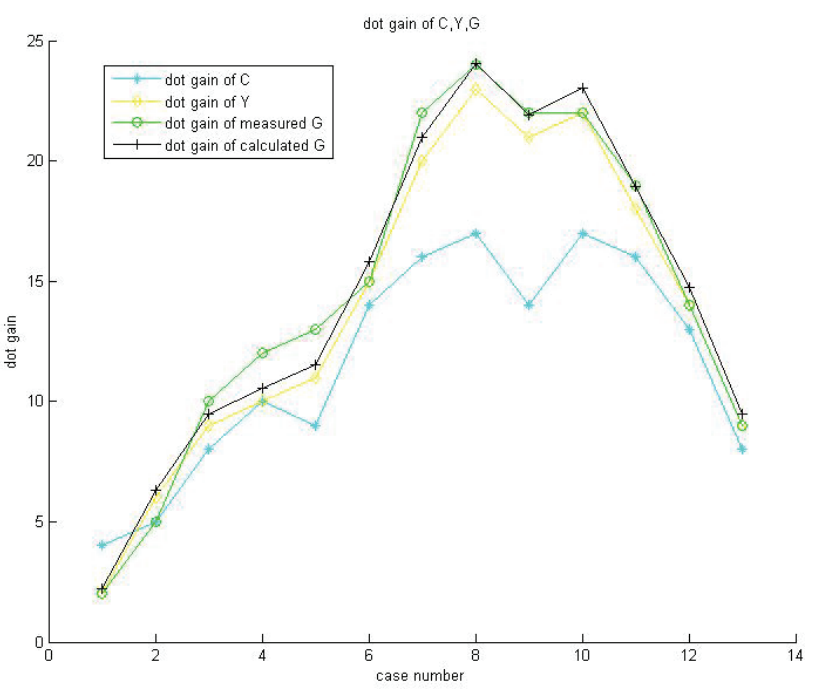

Figure 12 Dot gain of Cyan, Yellow, measured Green and Calculated Green
From Fig. 8 to Fig. 13, it is found that the model developed in this paper to calculate and to predict secondary colour dot gain has more efficiency in lighttone and mid-tone area of Red and Green while has some error in high light tone and shadow tone. For modeling and prediction of Blue, it is found that the model has more error than that for Red and Green, especially in the $50 \%$ tone area. So it is necessary to do some further research to the error area and the model for Blue. Moreover, it is also necessary to do research on the other types of printing for secondary dot gain.

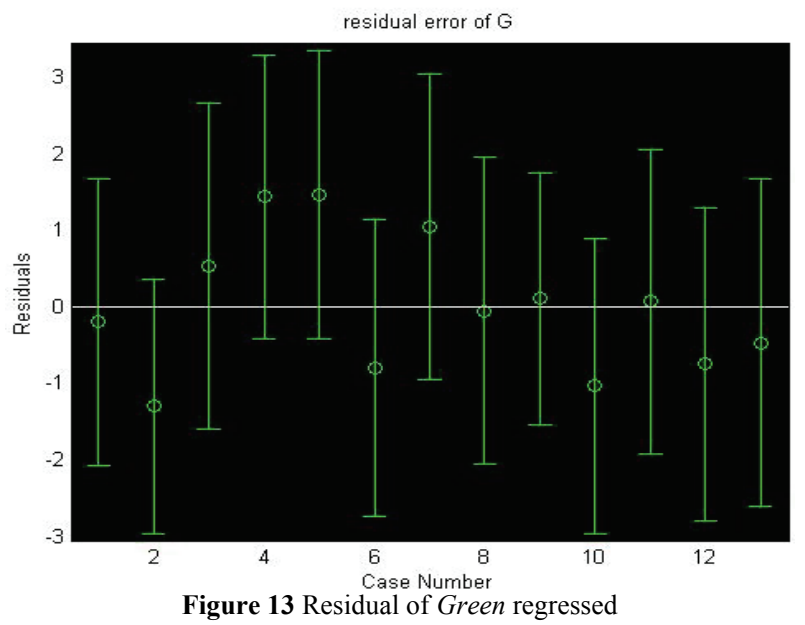

\section{Conclusion}

The purpose of digital printing is to enable the printing of high efficiency and of high quality reproduction. To obtain the qualitative reproduction depends on a series of parameters, e.g., paper, pigments and equipments, digital prepress image processing. However, one of the most important is the standardized and defined dot gain in a regular production process. Dot gain control is the most effective and simple method to control printing quality. The research in this paper confirmed that the screening dot is the basic printing element to reproduce continuous image and to form the printing image. On the basis of the obtained results and analysis, with the aim of increasing the quality of the printing product, the new dot gain control technologies should be recommended during the digital printing process.

From all the mentioned, the research in this paper established the model of the secondary colour dot gain according to the primary colour dot gain so that it was used to evaluate and to control the dot gain in a larger scope.

The secondary colour dot gain in electrostatic digital printing is studied by considering dot gain of the colour scales, Cyan, Magenta, Yellow, Blue, Red and Green. The relations between secondary colour dot gain and primary colour dot gain are also studied. Three primary colour scales, Cyan, Magenta, Yellow, and three secondary colour scales, Blue, Red and Green, are designed from 2 $\%$ to $90 \%$. The colour scales are output by electrostatic colour press and measured by spectrophotometer. The dot gain of the secondary colour is modeled according to the dot gain rules of the primary colour using multiple linear 
regression method. The results illustrate that the dot gain of secondary colour changes with the dot gain of primary colour synchronously, and that further research is needed to make for dot gain compensation and printing process control.

\section{Acknowledgements}

This work was financially supported by Shandong Province Science and Technology Development Project (Grant No. 2012YD08016), Ji'nan City Colleges and Universities Independent Innovation Project (Grant No. 201311032), and Director Fund of Key Laboratory of Pulp \& Paper Science and Technology (Qilu University of Technology), Ministry of Education, Ji'nan, China (Grant No. 08031310).

\section{References}

[1] Adams, J. M.; Dolin, P. A. Printing Technology $5^{\text {nd }}$. Delmar Thomson Learning, US. 2001.

[2] Namedanian, M.; Gooran, S. Characterization of Total Dot Gain by Microscopic Image Analysis. // Journal of Imaging Science and Technology. 55, 4(2011), pp. 405011-405017. DOI: 10.2352/J.ImagingSci.Technol.2011.55.4.040501

[3] Shevell, S. K. The Science of Colour $2^{\text {nd }}$. Elsevier, UK, 2003.

[4] Kipphan, H. Handbook of Print Media. Springer, Berlin, 2001. DOI: 10.1007/978-3-540-29900-4

[5] Chengfa, H. U. Printing Colour Science. Printing Industry Press, Beijing, 1993.

[6] Braun, G. J.; Fairchild, M. D. Gamut Mapping for Pictorial Images. // Technical Assoation of the Graphic Arts, TAGA Proceedings/Rochester, 1999, pp. 645-660.

[7] Zjakic, I.; Bates, I.; Mikovic, M. A Study of Dot Gain and Gamut for Prints Made with Highly Pigmented Inks. // Tehnicki vjesnik-Technical Gazette. 18, 2(2011), pp. 227235.

[8] Li, X. Z. Study on Colour Gamut Mapping Theory and Method Based on Colour Appearance Model of High Fidelity Colour Reproduction. South China University of Technology, China, 2012.

[9] Zheng, Y. Detection and Control of Printing Materials Quality. Chemical Industry Press, Beijing, China, 2010.

[10] Nussbaum, P.; Hardeberg, J. Y. Print Quality Evaluation and Applied Colour Management in Coldset Offset Newspaper Print. // Colour Research and Application. 37, 2(2012), pp. 82-91. DOI: 10.1002/col.20674

[11] Nystrom, D.; Norberg, O. Improved Spectral Vector Error Diffusion by Dot Gain Compensation. // The International Society for Optical Engineering, Proceedings of SPIE and T Electronic Imaging - Color Imaging XVIII: Displaying, Processing, Hardcopy, and Applications/USA, 2013, pp. 86520L-1-11.

[12] Berns, R. S. Principles of Colour Technology. John Wiley \& Sons, New York, 2000.

[13] Mesic, B. Printability of Polyethylene-Coated Paper and Paperboard. Karlstad University, Karlstad, 2006.

[14] Yang, L. A Unified Model of Optical and Physical Dot Gain in Print Colour Reproduction. // Journal of Imaging Science and Technology. 48, 4(2004), pp. 347-353.

[15] Olsson, R. Some Aspects on Flexographic Ink-Paper and Paperboard Coating Interaction. Karlstad University, Karlstad, 2007.

[16] Modric, D. Scattering and Light Transport in Printing Substrates. Faculty of Graphic Arts, University of Zagreb, Croatia, 2009.
[17] Huntsman, J. R. A New Model of Dot Gain and Its Application to a Multilayer Colour Proof. // Journal of Imaging Science and Technology. 13, 5(1987), pp. 136145 .

[18] Englund, C.; Veritas, A. Ink Flow Control by Multiple Models in An Offset Lithographic Printing Process. // Computers \& Industrial Engineering. 55, 3(2008), pp. 592605. DOI: 10.1016/j.cie.2008.01.019

[19] Bugnon, T.; Hersch, R. D. But is it an online shelflist?: recovering neugebauer colourant reflectances and inkspreading curves from printed colour images. // Colour Research and Application, 2013.

[20] Changjun, L.; Ronnier, L. M. Further Accelerating the Inversion of The Yule-Nielson Modified Neugebauer Model. // Color Science and Engineering Systems, Technologies, and Applicatrions, Final Program and Proceedings - IS and T/SID Colour Imaging Conference/Portland, 2008, pp. 84-88.

[21] Yule, J. A. C.; Nielsen W. J. The Penetration of Light into Paper and Its Effect on Halftone Reproductions. // Technical Association of the Graphic Arts, TAGA Proceedings/Rochester, 1951.

[22] Arney, J. S.; Engeldrum, P. G.; Zeng, H. Expanded MurrayDavies Model of Tone Reproduction in Halftone Imaging. // Journal of Imaging Science and Technology. 39, 6(1995), pp. 502-508.

[23] Gustavson, S. Dot Gain in Colour Halftones. Linkoping University, Linkoping, 1997.

\section{Authors' address}

Xiao-zhou Li, Ph.D.

Key Laboratory of Pulp \& Paper Science and Technology, Ministry of Education

Qilu University of Technology

250353, Ji'nan, China

Email: lixiaozhou2000@163.com

Jing-jing Liu, Assistant and researcher

Shandong University of Art \& Design

250353, Ji'nan, China

Email: foxliu919@163.com

Xue-lin Li, Assistant and researcher

School of Mechanical and Automotive Engineering

Qilu University of Technology

250353, Ji'nan, China

Email: kjclxl@126.com

Yu Liu, Prof.

School of Computer and Electron Information Engineering Qilu University of Technology and Shandong Yingcai University 250104, Ji'nan, China

Email: liuyu8619759@163.com

\section{Ai Xu, Assistant Prof.}

Qilu University of Technology

250353, Ji'nan, China

Email: 1xzrgb@126.com 